\title{
Pengaturan Tampilan Menurut Usia Pada Papan Iklan Digital Dengan Menggunakan Metode Jaringan Saraf Tiruan
}

\section{Teguh Adiaksa Wicaksono, ${ }^{*}$ Nachrowie, Irfan Mujahidin}

Teknik Elektro, Universitas Merdeka Malang, Jalan Taman Agung Karangbesuki Sukun Malang Indonesia

*teguh.adiaksa13@gmail.com

Kata Kunci :

Iklan

Open cv

Jaringan saraf tiruan Raspberry $P i$

\section{ABSTRAK}

Iklan dapat diartikan sebagai media informasi yang dapat diakses dengan mudah, efektif dan efesien. Iklan yang ada sementara ini bersifat global, yaitu tidak adanya filter untuk menampilkan jenis iklan berdasarkan usia. Padahal hal tersebut dapat berdampak kurang baik jika anak usia dini menyaksikan iklan yang dihasilkan untuk dewasa. Filter pada iklan dapat memanfaatkan kamera, yaitu dengan bantuan image processing. Filter dengan bantuan kamera ini adalah mengelompokkan setiap wajah yang terdeteksi berdasarkan usia. Maka diperoleh kesimpulan sebagai berikut: Penerapan citra digital pada pengaturan pendeteksian usia menggunakan opencv sebagai library yang digunakan serta menggunakan bahas pemrograman python yang di olah di dalam mini komputer yaitu raspberry pi. Sistem dapat mendeteksi adanya wajah dengan parameter usia pada anak 4-20 tahun dan dewasa 31-80 tahun pada pengujian seseorang dengan cepat dan akurat menggunakan metode jaringan saraf tiruan dengan sekema deep neural network sehingga tingkat akurasi wajah yaitu 99\% sehingga iklan dapat berubah dari iklan konten dewasa ataupun anak-anak.

Advertising can be interpreted as a medium of information that can be accessed easily, effectively, and efficiently. Existing ads are global, i.e. There is no filter to display ad types based on age. Even though this can have an adverse effect if an early child watches an advertisement produced for an adult. Filters on advertisements can utilize the camera, namely with the help of image processing. Filter with the help of this camera is to group each face that is detected by age. The following conclusions are obtained: The application of digital images in the age detection settings using Open $C V$ as a library that is used as well as using the python programming language processed on a mini-computer, the raspberry pi. The system can detect faces with age parameters in children 4-20 years and adults 31-80 years on someone's test quickly and accurately using the artificial neural network method with deep neural network schema so that the accuracy of the face is $99 \%$ so that advertising can change from advertising adult or children's content. 


\section{Pendahuluan}

Kehidupan manusia saat ini sudah memiliki kemajuan yang cukup pesat, khususnya pada bidang elektronika. Dengan adanya perkembangan ini, Ilmu elektronika dalam bidang kontrol dapat dilihat dari cara kerjanya secara otomatis ataupun dari perintah manusia[1][2]. Hal ini dapat dilihat dari peralatan yang dibuat. Alat tersebut dapat dioperasikan secara manual maupun otomatis[3][4]. Terhitung dari tahun 1970 model sistem kontrol mulai banyak digunakan dalam kehidupan di masyarakat[5].

Iklan dapat diartikan sebagai media informasi yang dapat diakses dengan mudah, efektif dan efesien. Banyak perusahaan yang menggunakan iklan sebagai sarana promosi ataupun mengenalkan produk baru kepada masyarakat[6]. Dengan menggunakan iklan penyampaian informasi berupa pesan untuk membujuk, pesan informatif dapat tersampaikan dengan baik[7][8]. Iklan yang ada sementara ini bersifat global, yaitu tidak adanya filter untuk menampilkan jenis iklan berdasarkan usia. Padahal hal tersebut dapat berdampak kurang baik jika anak usia dini menyaksikan iklan yang dihasilkan untuk dewasa[9]. Dampak iklan rokok pada anak usia dini dapat memberikan efek timbulnya rasa ingin tahu pada anak-anak sehingga menimbulkan rasa ingin merokok. Selain itu memberikan dorongan merokok tidak hanya pada kalangan anak-anak melainkan dapat mempengaruhi orang dewasa[10][11]. Dari segi pemasaran tersebut tidak akan efektif karena tidak tepat sasaran.

Filter pada iklan dapat memanfaatkan kamera, yaitu dengan bantuan image processing. Filter dengan bantuan kamera ini adalah mengelompokkan setiap wajah yang terdeteksi berdasarkan usia[12][13]. Pada penelitian ini semua wajah yang terdeteksi oleh kamera yang akan diolah oleh raspberry pi untuk dikelompokan berdasarkan usia dan iklan yang ditampilkan akan disesuaikan dengan usia tersebut[14][15]. Berdasarkan uraian di atas maka dibuatlah "Pengaturan Tampilan Menurut Usia Pada Papan Iklan Digital Dengan Menggunakan Metode Jaringan Saraf Tiruan" yang menggunakan teknologi raspberry pi sebagai pengolah data Informasi[16].

Berdasarkan permasalahan tersebut, maka penulis membuat penulisan yang berjudul "pengaturan tampilan menurut usia pada papan iklan digital dengan menggunakan metode jaringan saraf tiruan" pada perancangan penelitian yang dilakukan terkait dengan implementasi library openCV serta penerapan pengolahan citra digital pada aplikasi yang dapat menangkap objek wajah dengan menggunakan kamera serta diproses oleh raspberry pi sebagai mikro komputer[17][18]. Konsep yang digunakan adalah input video/gambar untuk mendeteksi posisi objek wajah.

\section{Metode Penulisan}

\subsection{Rancangan Penelitian}

Hal yang terpenting harus diperhatikan dalam membuat sesuatu perancangan yaitu diagram blok yang mencangkup cara kerja dari alat yang dirancang, kemudian karakteristik komponen yang digunakan, keselurahan blok diagram implementasi pada alat papan iklan digital menurut usia dengan menggunakan metode jaringan saraf tiruan[19][20]. 


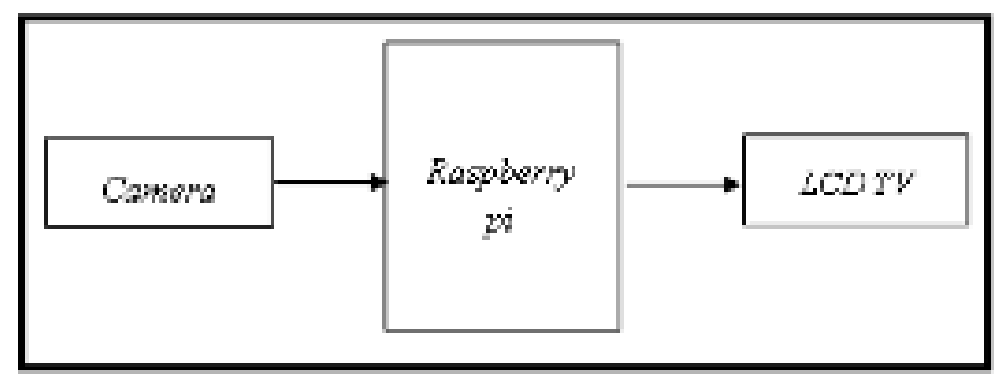

Gambar 1 Blok Diagram

Pada Gambar 1. adalah blok diagram yang menjelaskan sistem kerja dari alat yang digunakan pada penelitian dan pengembangan pada tugas akhir ini adalah mode input masukan pada sistem papan iklan digital. Input tersebut merupakan suatu program yang dibuat untuk menangkap gambar yang nantinya akan diolah dalam raspberry pi yang berfungsi mengolah data dan mengirimkan hasil yang akan ditampilkan ke layar LCD TV[21][22].

\subsection{Flowchart Program}

Flowchart atau diagram alir merupakan sebuah gambaran yang digunakan untuk mempermudah penulis dengan membuat secara grafik berupa langkah-langkah dan urutanurutan dari prosedur kerja dalam suatu program yang akan dibuat[23][24]. Flowchart adalah bagan yang menunjukan proses dari alur kerja yang hendak dikerjakan atau sedang dikerjakan. Pada suatu sistem yang dilakukan secara menyeluruh untuk menjelaskan urutan pada prosedur kerja yang ada didalam sistem guna mempermudah pembaca. Adapun rancangan yang telah dibuat[25].

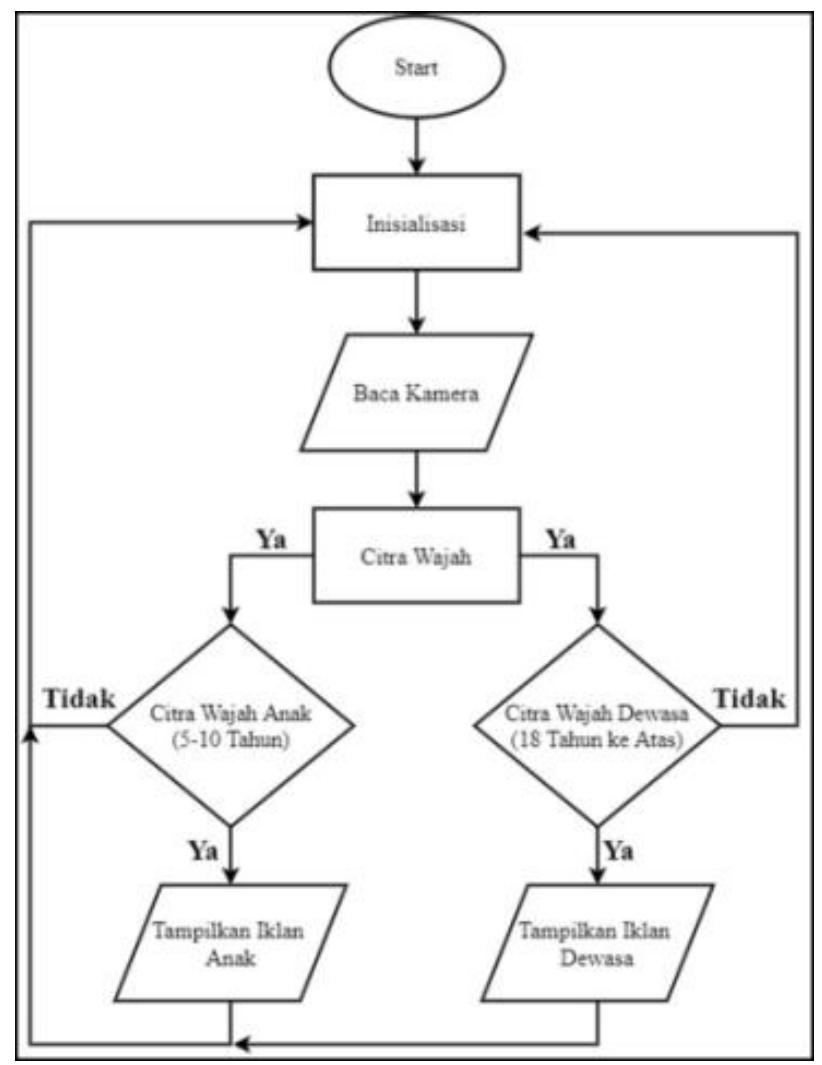

Gambar 2 Flowcart Program 


\subsection{Skematik Rangkaian}

Berikut merupakan gambaran skematik dari rangkaian yang akan dibuat. Pada bagian ini akan ditampilkan komponen yang dipakai untuk merancang perangkat papan iklan digital dan tiap perangkap saling dihubungkan[26][27]. Desain skematik rangkaian hardware pada sistem ini dengan kontrol berupa mini pc dan hardware kamera difungsikan untuk menangkap citra digital yang diolah pada raspberry pi dan raspberry pi mengirim data yang telah diproses pada LCD TV[28].

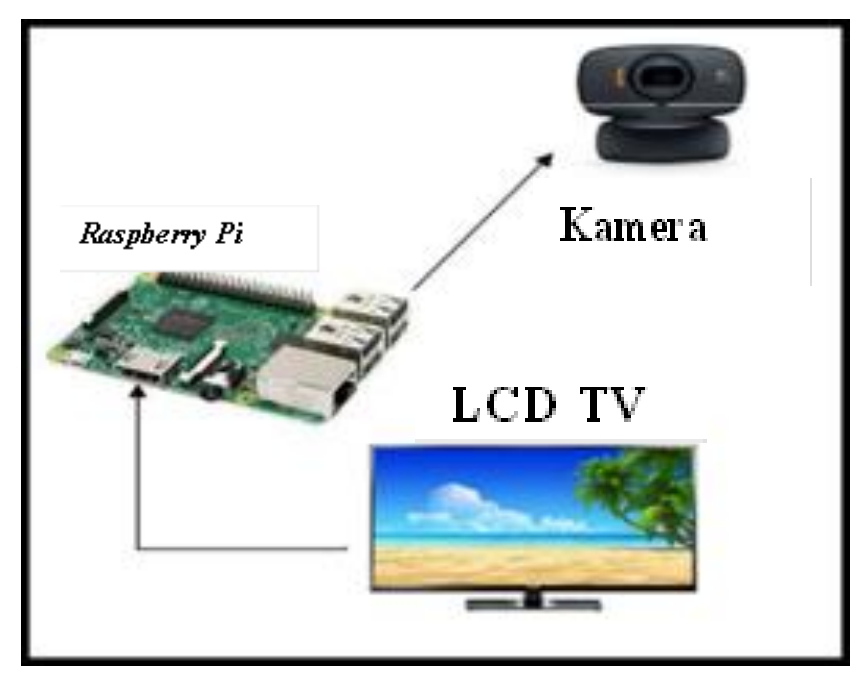

Gambar 3 Desain Perancangan Hardware

Gambar 3. menunjukkan perancangan hardware raspberry pi sebagai mini pc untuk pengolahan program dan pengolahan citra digital sebagai deteksi objek yang akan di proses, hardware kamera dihubungkan pada port USB raspberry pi yang tersedia sebagai komunikasi antara kamera dengan raspberry pi dan juga sebagai penangkap citra digital yang akan di deteksi[29]. Berikut bagian kecil program yang merupakan proses pengambilan data training yang dilakukan pada penelitian ini:

Import imutils

import cv2

import time

from ffpyplayer.player import MediaPlayer

face_cascade $=$ cv2.CascadeClassifier('haarcascade_frontalface_alt.xml')

cam $=\mathrm{cv} 2$. VideoCapture $(0)$

cam.set(cv2.CAP_PROP_FRAME_WIDTH, 640)

cam.set(cv2.CAP_PROP_FRAME_HEIGHT, 480)

cam.set(cv2.CAP_PROP_FPS, 32)

rawCapture $=$ cam

MODEL_MEAN_VALUES $=(78.4263377603,87.7689143744,114.895847746)$

age_list=['(0, 2)','(4, 6)','(8, 12)','(15, 20)','(25, 32)','(38, 43)','(48, 53)','(60, 100)']

gender_list $=$ ['Male', 'Female']

age_arr $=[]$ 
age_index $=0$

time.sleep $(0.1)$

Pengujian dengan berbagai variasi usia pada penedeteksian oleh kamera terhadap objek yang dideteksi guna mengetahui kondisi optimal pembacaan masing-masing sensor kamera, yang nanti akan digunakan sebagai acuan kamera dapat mendeteksi wajah sehingga tidak membutuhkan waktu yang terlalu lama[30].

\section{Hasil dan Pembahasan}

Untuk kamera yang digunakan adalah webcam Logitech B525 full HD dengan resolusi maksimal 1920x1080 pixel yang berfungsi sebagai penangkap citra dari objek dengan hasil yang detail dan cerah. Perangkat kamera ini sebagai pendeteksi objek berupa wajah yang akan diproses pada raspberry pi

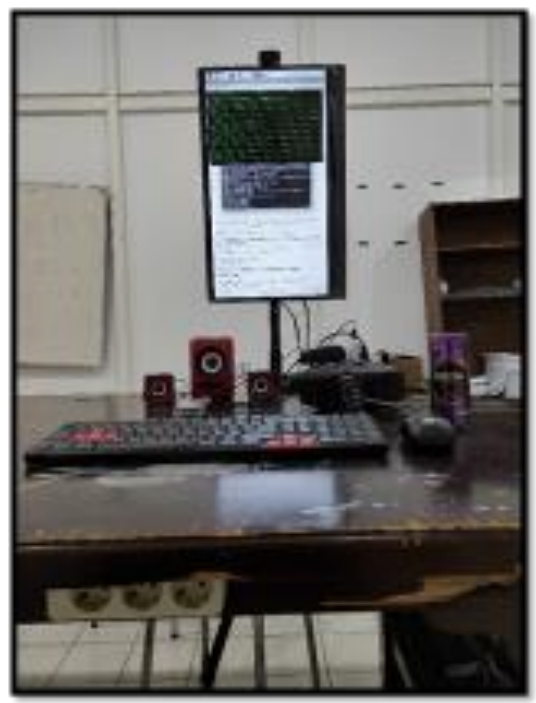

Gambar 4 Tampilan Pengujian Perangkat Kamera pada Raspberry Pi

Pada gambar 4. merupakan perangkat kamera yang dihubungkan pada raspberry pi yang akan ditampilkan pada layar LCD TV sebagai hasil proses.

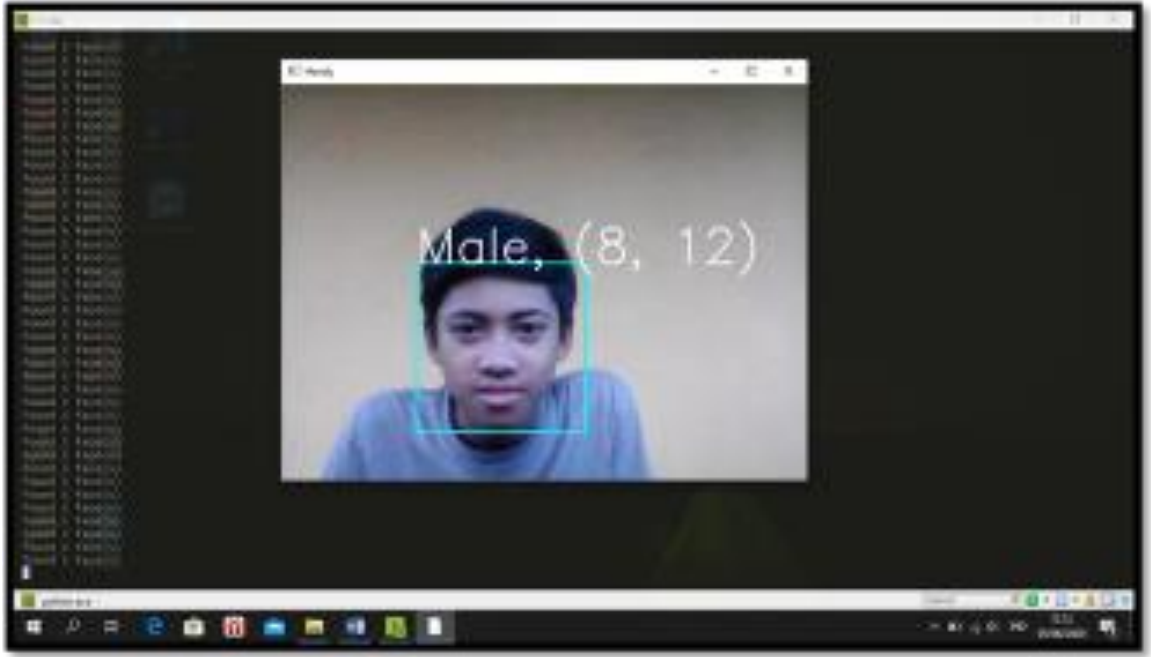

Gambar 5 Hasil deteksi usia 8-12 tahun 
Gambar diatas menunjukkan hasil wajah yang telah terdeteksi olah kamera menggunakan pemrograman python dengan library OpenCV.

Langkah awal dalam melakukan deteksi wajah adalah melakukan training data set agar program dapat menyimpan berbagai klasifikasi yang membentuk skema model wajah, selanjutnya adalah kamera akan disiapkan untuk mengambil data kamera secara real time. Pada pengujian deteksi wajah yang akan dilakukan menggunakan 4 sampel wajah berbeda dan kamera akan mengambil sampel ini menjadi input dari kamera yang akan terdeteksi untuk diproses pada raspberry pi.

Dalam pengujian ini terdapat kamera dan anak usia dibawah 5 tahun sebagai subjek uji. Terdapat kamera dan LCD sebagai media untuk menampilkan iklan. Berikut merupakan uji akurasi pada anak-anak untuk mendeteksi usia.

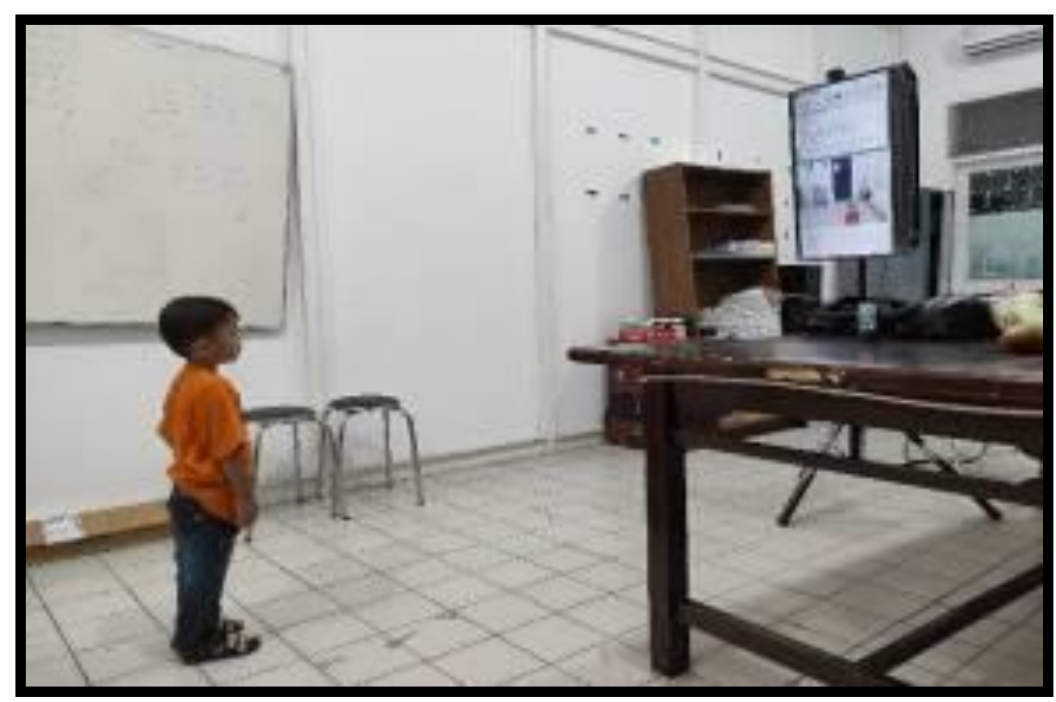

Gambar 6 Tampilan Deteksi Usia pada Anak-anak

Dapat dilihat dari gambar 6. merupakan tampilan percobaan pengolahan citra dengan media wajah anak-anak. keseluruhan struktur wajah yang telah dimasukan beberapa sampel, proses penentuan wajah anak-anak maka langkah yang dilakukan program adalah menentukan usia yang telah di training dari bebrapa sampel yang telah dimasukan kedalam program opencv.

Tabel 1 Hasil Pengujian Deteksi Kamera Pada Anak-anak

\begin{tabular}{lcccc}
\hline \multirow{2}{*}{ No } & \multirow{2}{*}{$\begin{array}{c}\text { Sampel } \\
\text { Pengujian }\end{array}$} & Usia & & \multicolumn{2}{c}{ Hasil } \\
\cline { 3 - 5 } & & 4,3 & Terdeteksi & $\begin{array}{c}\text { Tidak } \\
\text { Terdeteksi }\end{array}$ \\
\hline \multirow{3}{*}{1} & Anak-anak & 5,8 & $\checkmark$ & - \\
& 4-8 tahun & 6,4 & $\checkmark$ & - \\
& & 7,9 & $\checkmark$ & - \\
& & 8,10 & $\checkmark$ & - \\
\hline \multirow{3}{*}{2} & Anak-anak & 9,3 & $\checkmark$ & - \\
& 8-12 tahun & 10,1 & $\checkmark$ & - \\
& & 11,2 & $\checkmark$ & - \\
\hline 3 & Anak-anak & 12,4 & $\checkmark$ & - \\
\hline
\end{tabular}




\begin{tabular}{ccccc}
\hline \multirow{2}{*}{ No } & \multirow{2}{*}{$\begin{array}{c}\text { Sampel } \\
\text { Pengujian }\end{array}$} & Usia & \multicolumn{2}{c}{ Hasil } \\
\cline { 3 - 5 } & & Terdeteksi & $\begin{array}{c}\text { Tidak } \\
\text { Terdeteksi }\end{array}$ \\
\cline { 3 - 5 } & $12-16$ tahun & 14,6 & $\checkmark$ & - \\
& 15,3 & $\checkmark$ & - \\
& & 16,1 & $\checkmark$ & - \\
\hline \multirow{4}{*}{4} & Anak-anak & 17,4 & $\checkmark$ & - \\
& 16,5 & $\checkmark$ & - \\
& $16-20$ tahun & 19,7 & $\checkmark$ & - \\
& & 20,8 & $\checkmark$ & - \\
\hline
\end{tabular}

Berdasarkan pengujian ini didapatkan hasil deteksi yang ditunjukan pada gambar

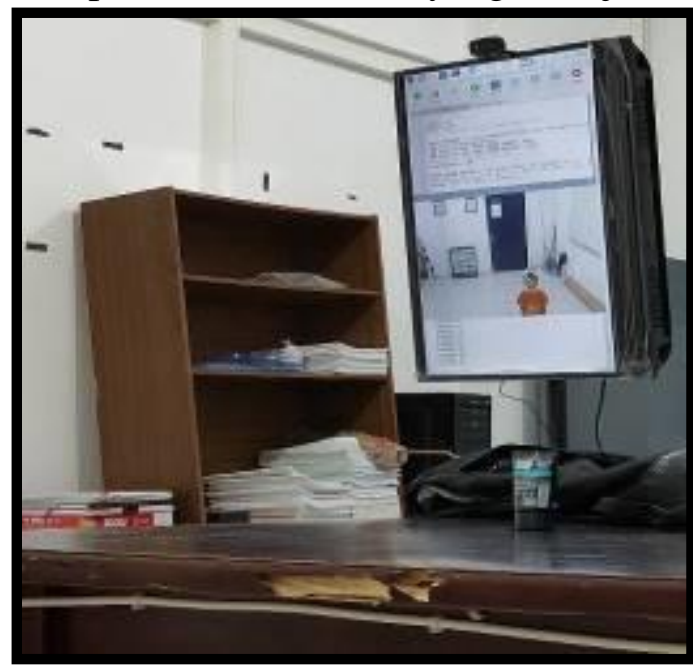

Gambar 7 Tampilan Hasil Deteksi Usia pada Anak-anak

Pada penelitian ini terdapat kamera dan usia orang dewasa sebagai subjek uji. Terdapat kamera dan LCD sebagai media untuk menampilkan iklan. Berikut merupakan uji akurasi pada orang dewasa untuk mendeteksi usia. Berdasarkan pengujian ini dapat dilihat pada gambar 7.

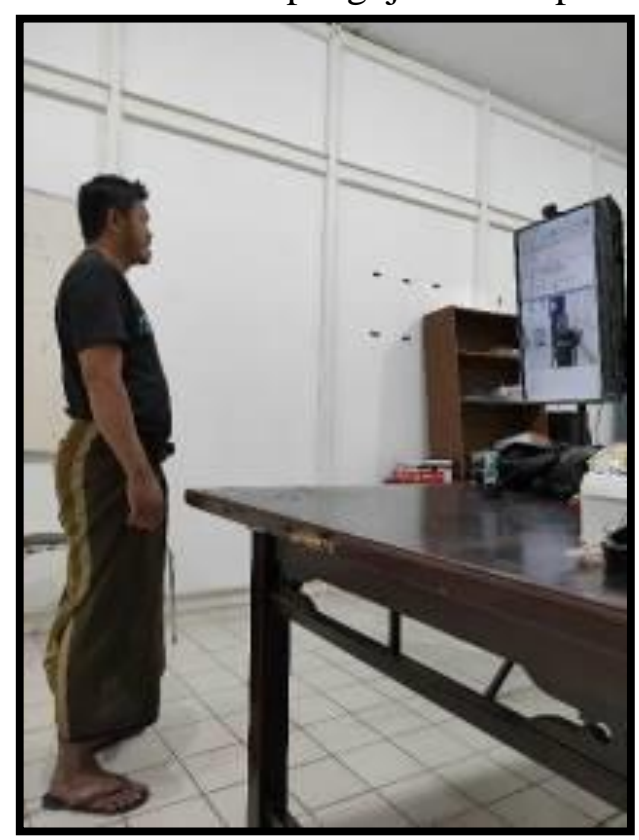

Gambar 8 Tampilan Deteksi Usia pada orag Dewasa 
Gambar 8. merupakan tampilan percobaan pengolahan citra dengan media wajah dewasa. Keseluruhan struktur wajah yang telah dimasukan beberapa sampel, proses penentuan wajah dewasa maka langkah yang dilakukan program adalah menentukan usia yang telah di training dari beberapa sampel yang telah dimasukan kedalam program opencv.

Langkah awal dalam melakukan deteksi wajah adalah melakukan training data set agar program dapat menyimpan berbagai klasifikasi yang membentuk skema model wajah, selanjutnya adalah kamera akan disiapkan untuk mengambil data kamera secara real time. Pada pengujian deteksi wajah yang akan dilakukan menggunakan sampel wajah dan kamera akan mengambil sampel ini menjadi input dari kamera yang akan terdeteksi untuk diproses pada raspberry pi.

Tabel 2 merupakan hasil uji deteksi wajah yang akan digunakan untuk pendeteksian usia dewasa.

\begin{tabular}{|c|c|c|c|c|}
\hline \multirow[b]{2}{*}{ No } & \multirow[b]{2}{*}{$\begin{array}{l}\text { Sampel } \\
\text { Pengujian }\end{array}$} & \multirow[b]{2}{*}{ Usia } & \multicolumn{2}{|c|}{ Hasil } \\
\hline & & & Terdeteksi & $\begin{array}{l}\text { Tidak } \\
\text { Terdeteksi }\end{array}$ \\
\hline \multirow{5}{*}{1} & & 21,3 & $\checkmark$ & - \\
\hline & Orang & 22,7 & $\checkmark$ & - \\
\hline & Dewasa & 23,5 & $\checkmark$ & - \\
\hline & $21-25$ & 24,2 & $\checkmark$ & - \\
\hline & & 25,6 & $\checkmark$ & - \\
\hline \multirow{5}{*}{2} & & 26,8 & $\checkmark$ & - \\
\hline & Orang & 27,5 & $\checkmark$ & - \\
\hline & Dewasa & 28,3 & $\checkmark$ & - \\
\hline & $26-30$ & 29,2 & $\checkmark$ & - \\
\hline & & 30,1 & $\checkmark$ & - \\
\hline \multirow{5}{*}{3} & & 31,8 & $\checkmark$ & - \\
\hline & Orang & 44,4 & $\checkmark$ & - \\
\hline & Dewasa & 45,9 & $\checkmark$ & - \\
\hline & $31-80$ & 50,3 & $\checkmark$ & - \\
\hline & & 80,3 & $\checkmark$ & - \\
\hline
\end{tabular}

\section{Kesimpulan}

Berdasrakan hasil yang didapat dalam penelitian yang dilakukan, maka diperoleh kesimpulan sebagai berikut: Penerapan citra digital pada pengaturan pendeteksian usia menggunakan opencv sebagai library yang digunakan serta menggunakan bahas pemrograman python yang di olah di dalam mini komputer yaitu raspberry pi. Dari komponen tersebut yang metode yang di optimalakan berupa training data set agar program dapat menyimpan berbagai klasifikasi yang membentuk skema model wajah, selanjutnya adalah kamera akan disiapkan untuk mengambil data kamera secara real time. Sistem dapat mendeteksi adanya wajah dengan parameter usia pada anak 4-20 tahun dan dewasa 31 - 80 tahun pada pengujian seseorang dengan cepat dan akurat menggunakan metode jaringan saraf tiruan dengan sekema deep neural network sehingga tingkat akurasi wajah yaitu 99\% sehingga iklan dapat berubah dari iklan konten dewasa ataupun anak-anak. 


\section{Daftar Pustaka}

W. M. Dessy And A. Irawan, "Perbandingan Metode Jaringan Syaraf Tiruan Backpropagation Dan Learning Vector Quantization Pada Pengenalan Wajah,” J. Komput. Dan Inform., 2012.

L. Liu Et Al., "Deep Learning For Generic Object Detection: A Survey," Int. J. Comput. Vis., 2019.

R. Yuwono, I. Mujahidin, A. Mustofa, And Aisah, "Rectifier Using Ufo Microstrip Antenna As Electromagnetic Energy Harvester," Adv. Sci. Lett., 2015.

I. Mujahidin, "Directional 1900 Mhz Square Patch Ring Slot Microstrip Antenna For Wcdma," Jeemecs (Journal Electr. Eng. Mechatron. Comput. Sci., 2019.

I. Mujahidin, R. Yuwono, And A. Mustofa, "Rancang Bangun Rectifier Antenna Mikrostrip Ufo Pada Frekuensi Ultra Wideband (Uwb) Sebagai Pemanen Energi Elektromagnetik," J. Mhs. Teub, Vol. 3, No. 2, 2015.

M. T. Prakarsa, D. Wahyuni, N. Rachman, And I. Mujahidin, "Optimasi Sistem Komunikasi Dari Ht Dengan Hp Dalam Pelaksanaan Tugas Operasi Tni Ad Menggunakan Metode Dtmf," Jasiek (Jurnal Apl. Sains, Informasi, Elektron. Dan Komputer), 2019.

J. Lasmono, A. P. Sari, E. Kuncoro, And I. Mujahidin, "Optimasi Kerja Peluncur Roket Pada Robot Roda Rantai Untuk Menentukan Ketepatan Sudut Tembak," Jasiek (Jurnal Apl. Sains, Informasi, Elektron. Dan Komputer), 2019.

W. M. Dessy And A. Irawan, "Perbandingan Metode Jaringan Syaraf Tiruan Backpropagation Dan Learning Vector Quantization Pada Pengenalan Wajah,” J. Komput. Dan Inform., 2012.

L. Liu Et Al., "Deep Learning For Generic Object Detection: A Survey," Int. J. Comput. Vis., 2019.

R. Yuwono, I. Mujahidin, A. Mustofa, And Aisah, "Rectifier Using Ufo Microstrip Antenna As Electromagnetic Energy Harvester," Adv. Sci. Lett., 2015.

I. Mujahidin, "Directional 1900 Mhz Square Patch Ring Slot Microstrip Antenna For Wcdma," Jeemecs (Journal Electr. Eng. Mechatron. Comput. Sci., 2019.

I. Mujahidin, R. Yuwono, And A. Mustofa, "Rancang Bangun Rectifier Antenna Mikrostrip Ufo Pada Frekuensi Ultra Wideband (Uwb) Sebagai Pemanen Energi Elektromagnetik," J. Mhs. Teub, Vol. 3, No. 2, 2015.

M. T. Prakarsa, D. Wahyuni, N. Rachman, And I. Mujahidin, "Optimasi Sistem Komunikasi Dari Ht Dengan Hp Dalam Pelaksanaan Tugas Operasi Tni Ad Menggunakan Metode Dtmf," Jasiek (Jurnal Apl. Sains, Informasi, Elektron. Dan Komputer), 2019.

J. Lasmono, A. P. Sari, E. Kuncoro, And I. Mujahidin, “Optimasi Kerja Peluncur Roket Pada 
Robot Roda Rantai Untuk Menentukan Ketepatan Sudut Tembak," Jasiek (Jurnal Apl. Sains, Informasi, Elektron. Dan Komputer), 2019.

I. Mujahidin, S. H. Pramono, And A. Muslim, "5.5 Ghz Directional Antenna With 90 Degree Phase Difference Output," 2018.

I. Mujahidin And B. F. Hidayatulail, "2.4 Ghz Square Ring Patch With Ring Slot Antenna For Self Injection Locked Radar,” Jeemecs (Journal Electr. Eng. Mechatron. Comput. Sci., Vol. 2, No. 2, 2019.

M. Wibowo, S. Suprayogi, And I. Mujahidin, "Rancang Bangun Sistem Pengamanan Rak Senjata M16 Menggunakan Rfid Dan Fingerprint," Jasiek (Jurnal Apl. Sains, Informasi, Elektron. Dan Komputer), Vol. 1, No. 2, Pp. 134-142, 2019.

E. Endrayana, D. H. S. Wahyuni, N. Nachrowie, And I. Mujahidin, "Variasi Ground Plane Antena Collinear Pada Pemancar Telivisi Analog Dengan Frekuensi Uhf 442 Mhz," Jasiek (Jurnal Apl. Sains, Informasi, Elektron. Dan Komputer), Vol. 1, No. 2, Pp. 149-156, 2019.

D. F. C. Kusuma, D. A. Prasetya, F. Kholid, And I. Mujahidin, "Evaluasi Database Senjata Untuk Sistem Keamanan Menggunakan Fuzzy Logic," Jasiek (Jurnal Apl. Sains, Informasi, Elektron. Dan Komputer), Vol. 1, No. 2, Pp. 111-116, 2019.

A. E. Pambudi, L. Maajid, J. Rohman, And I. Mujahidin, "Aplikasi Penggunaan Joystick Sebagai Pengendalian Remote Control Weapon Station (Rcws) Senjata Mesin Ringan (Smr)," Jasiek (Jurnal Apl. Sains, Informasi, Elektron. Dan Komputer), Vol. 1, No. 2, Pp. 98-105, 2019.

S. C. Satapathy, V. Bhateja, And A. Joshi, "Proceedings Of The International Conference On Data Engineering And Communication Technology : Icdect 2016. Volume 2," Int. J. Eng. Res. Technol., 2020.

S. K. Sugiarto, I. Mujahidin, And A. B. Setiawan, "2, 5 Ghz Antena Mikrostrip Polarisasi Circular Model Patch Yin Yang Untuk Wireless Sensor," Jeecae (Journal Electr. Electron. Control. Automot. Eng., Vol. 4, No. 2, Pp. 297-300, 2019.

B. F. Hidayatulail And I. Mujahidin, "Potential Of 77, $78 \mathrm{Mw}$ Red Diode Laser For Photodynamic,” Jeemecs (Journal Electr. Eng. Mechatron. Comput. Sci., Vol. 2, No. 2, 2019.

T. Nguyen, S. W. Chen, S. S. Shivakumar, C. J. Taylor, And V. Kumar, "Unsupervised Deep Homography: A Fast And Robust Homography Estimation Model," Ieee Robot. Autom. Lett., 2018.

I. Mujahidin And P. S. Arinda, "Antena Compact Double Square Marge 2, 6ghz Dengan Output Perbedaan Fase 90 Derajat Untuk Aplikasi Lte," Jeecae (Journal Electr. Electron. Control. Automot. Eng., Vol. 4, No. 2, Pp. 273-278, 2019. 
M. S. Ramadhan, L. Novamizanti, And E. Susatio, "Sistem Pengenalan Individu Berbasis Citra Wajah 3d Dengan Jaringan Syaraf Tiruan,” Techné J. Ilm. Elektrotek., 2019.

R. Yuwono And I. Mujahidin, "Rectifier Using Uwb Microstrip Antenna As Electromagnetic Energy Harvester For Gsm, Cctv And Wi-Fi Transmitter,” J. Commun., 2019.

I. Mujahidin, D. A. Prasetya, A. B. Setywan, And P. S. Arinda, "Circular Polarization 5.5 Ghz Double Square Margin Antenna In The Metal Framed Smartphone For Sil Wireless Sensor," In 2019 International Seminar On Intelligent Technology And Its Applications (Isitia), 2019, Pp. 1-6.

D. A. Prasetya, A. Sanusi, G. Chandrarin, E. Roikhah, I. Mujahidin, And R. Arifuddin, "Small And Medium Enterprises Problem And Potential Solutions For Waste Management," $J$. Southwest Jiaotong Univ., Vol. 54, No. 6, 2019.

D. A. Ayubi, D. A. Prasetya, And I. Mujahidin, "Pendeteksi Wajah Secara Real Time Pada 2 Degree Of Freedom (Dof) Kepala Robot Menggunakan Deep Integral Image Cascade," Cyclotr. J. Tek. Elektro, Vol. 3, No. 1, 2020.

T. A. S, A. Rabi', D. Minggu, And I. Mujahidin, "Frequency Hopping Video Real Time Untuk Pengamanan Data Pengintaian Operasi Inteligence Tni," Jasiek (Jurnal Apl. Sains, Informasi, Elektron. Dan Komputer), 2019.

D. A. Prasetya, A. Sanusi, G. Chandrarin, E. Roikhah, I. Mujahidin, And R. Arifuddin, "Community Culture Improvisation Regarding Waste Management Systems And Per Capita Income Increase,” J. Southwest Jiaotong Univ., Vol. 54, No. 6, 2019.

V. Robbyvalentino, N. Nachrowie, D. W, And I, Mujahidin, "Rancang Bangun Sistem Penilaian Kesegaran Jasmani A Di Jajaran Tni-Ad Berbasis Rfid," Jasiek (Jurnal Apl. Sains, Informasi, Elektron. Dan Komputer), Vol. 2, No. 1, Pp. 98-106, 2020.

I. Mujahidin, "Pll (Phase Locked Loop)," Http://Antenapropagasi.Blogspot.Com/2018/11/PllPhase-Locked-Loop.Html. 2018.

I. Mujahidin, "Smart Transducers," Http://Antenapropagasi.Blogspot.Com/2018/11/SmartTransducers.Html. 2018.

I. Mujahidin, "Directional Couplers," Http://Antenapropagasi.Blogspot.Com/2018/11/Directional-Couplers.Html, No. 1. 2018.

I. Mujahidin, D. A. Prasetya, Nachrowie, S. A. Sena, And P. S. Arinda, "Performance Tuning Of Spade Card Antenna Using Mean Average Loss Of Backpropagation Neural Network," Int. J. Adv. Comput. Sci. Appl., 2020. 